\title{
Reinforcement learning in dendritic structures
}

\author{
Mathieu Schiess", Robert Urbanczik, Walter Senn \\ From Twentieth Annual Computational Neuroscience Meeting: CNS*2011 \\ Stockholm, Sweden. 23-28 July 2011
}

The discovery of binary dendritic events such as local NMDA spikes in dendritic subbranches led to the suggestion that dendritic trees could be computationally equivalent to a 2-layer network of point neurons [1], with a single output unit re presented by the soma, and input units represented by the dendritic sub-branches where synapses are clustered[2]. In a such architecture, NMDA spikes transport information from synaptic input into action potentials.

Although this interpretation endows a neuron with a high computational power, it is functionally not clear why nature would have preferred the dendritic solution with a single but complex neuron, as opposed to the network solution with many but simple units. We show that the dendritic solution has a distinguished advantage over the network solution when considering different learning tasks. Its key property is that the dendritic branches receive an immediate feedback from the back-propagation of the action potential and (more general, of the somatic membrane potential deflections), while in the corresponding network architecture the feedback would require additional backpropagating connections to the input units. Assuming a reinforcement learning scenario we formally derive a learning rule for the synaptic contacts on the individual dendritic trees which depends on the presynaptic activity, the local NMDA spikes, the somatic action potential, and a delayed reinforcement signal. We test the model for two scenarios: the learning of binary classifications and of precise spike timings. We show that the immediate feedback represented by the backpropagating action potential supplies the individual dendritic subbranches with enough information to efficiently adapt their synapses and to speed up the learning process. For the binary classifications task, we show that the global performance increased with the number of dendritic sub-

\footnotetext{
* Correspondence: schiess@pyl.unibe.ch

Department of Physiology, University of Bern, Bern 3012, Switzerland
}

Full list of author information is available at the end of the article branches. We show that spacial information can be stores in precise spike and used in a navigation task.

Published: 18 July 2011

\section{References}

1. Poirazi P, Brannon T, Mel BW: Pyramidal Neuron as Two-Layer Neural Network. Neuron 2003, 37:989-999.

2. Larkum ME, Nevian T, Sandler M, Polsky E, Schiller J: Synaptic Integration in Tuft Dendrites of Layer 5 Pyramidal Neurons: A New Unifying Principle. Science 2009, 325:756-760.

doi:10.1186/1471-2202-12-S1-P293

Cite this article as: Schiess et al:: Reinforcement learning in dendritic structures. BMC Neuroscience 2011 12(Suppl 1):P293.

Submit your next manuscript to BioMed Central and take full advantage of:

- Convenient online submission

- Thorough peer review

- No space constraints or color figure charges

- Immediate publication on acceptance

- Inclusion in PubMed, CAS, Scopus and Google Scholar

- Research which is freely available for redistribution

Submit your manuscript at www.biomedcentral.com/submit

\section{() Biomed Central}

C Biomed Central

(C) 2011 Schiess et al; licensee BioMed Central Ltd. This is an open access article distributed under the terms of the Creative Commons Attribution License (http://creativecommons.org/licenses/by/2.0), which permits unrestricted use, distribution, and reproduction in any medium, provided the original work is properly cited. 